\title{
Distribution of convective energy at upper level in South Korea and the possibility of artificial showery rain caused by activated CAPE
}

\author{
Sang-Min Lee $\cdot$ Hi-Ryong Byun
}

Received: 12 May 2010 / Accepted: 16 January 2011 /Published online: 15 February 2011

(C) The Author(s) 2011. This article is published with open access at Springerlink.com

\begin{abstract}
This paper reports a theoretical study on the possibility of inducing artificial showery rain using the convective available potential energy, which is naturally stored in the troposphere. We calculated the environmental parameters (frequency of climatic values, extreme value of stability index, etc.) in the upper troposphere using rawinsonde data from six main stations in Korea from 2001 to 2008 and examined the temporal spatial convective energy according to region. Our results showed that convective available potential energy, which can induce artificial rainfall, existed in the troposphere mainly in summer and were low in other seasons. Its value was found to be highest during late afternoon and in inland regions. We examined the vertical structure of the atmosphere using moisture convergence and vertical velocity (omega) and found that precipitation occurred under strong real latent instability conditions with high convective available potential energy $(>3,000 \mathrm{~J} / \mathrm{kg})$ in summer and was characterized by moisture convergence at 1,000 $400 \mathrm{hPa}$, moisture divergence at $400-300 \mathrm{hPa}$, and continuous ascending air current at 1,000-300 hPa $(-\omega)$, on average. However, precipitation still did not occur in more than half the cases with high convective available potential energy because, according to the analysis, convective rainfall is affected to a greater extent by the value of convective inhibition than by convective available potential energy. It was also verified that in spite of zero convective
\end{abstract}

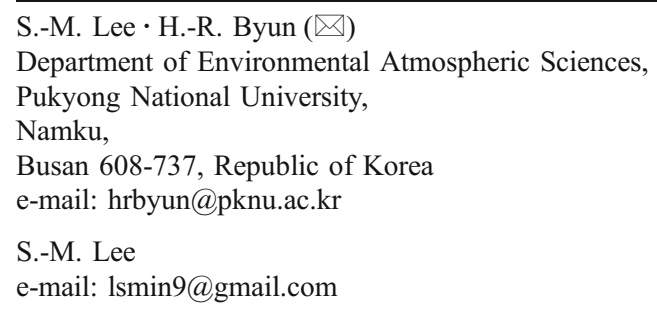

inhibition, if the updrafts at a lower level were not sufficient to generate high convective available potential energy at a level higher than the level of free convection, convective rainfall would not occur under real latent instability. Therefore, we suggest it might be possible during the summer to secure the water resources in regions without precipitation by inducing ascending air current artificially under unstable atmospheric conditions to induce showery rain.

\section{Introduction}

Over $50 \%$ of the annual precipitation in Korea occurs during the summer (Ho and Kang 1988). This is because the influx of water vapor is intensified during the summer due to the influence of moist southwesterly wind and typhoons, and the water vapor often changes into showery rain due to the instability of the atmosphere. Thus, the precipitation depends on the instability of the upper atmosphere.

The instability of the upper atmosphere in Korea has been previously studied, but the data was collected over short periods of time and only a few observation stations were used. Furthermore, most studies examined thunderstorm conditions and showed that air mass thunderstorms developed as a result of conditional instability in the lower atmospheric layer (Heo et al. 1994), the distribution of potential wet-bulb temperature in the lower layer (Kim and Lee 1994), and the re-production of convective cells in the process of nonlinear advection (Son et al. 2000). However, these studies focused on the characteristics of atmosphere in a very unstable state that appears during the development of the thunderstorm. Hence, the climatological temporal and spatial characteristics were not observed.

Eom et al. (2008), in a climatological study of the upper atmosphere in Korea, showed that the stability index and 
the environmental parameters were influenced by the geographical position of the station and the seasonal variation of the vertical structure of the atmosphere due to solar energy. They analyzed the upper atmosphere rawinsonde data of 5 stations in Korea for the period 1997-2006. Outside of Korea, extensive studies have been carried out on upper-atmospheric conditions using long-term accumulated data. In those studies, researchers mainly estimated the threshold value for significant weather events or studied the climatology of the observation data (Bischoff et al. 2007; Chuda and Niino 2005; Craven and Brooks 2004; Derubertis 2006; Rasmussen et al. 1998; Romero et al. 2007; Wang et al. 2000).

Although the annual precipitation in Korea is above the average annual precipitation in the world, almost half of that precipitation discharges into the sea immediately after the rain because there are so many high mountains where the stream gradient is steep. As a result, Korea is one of the countries facing water shortage, as determined by Population Action International (PAI 2000), and is classified as a low water resources environment in the Water Poverty Index developed by the Centre for Ecology and Hydrology (Centre for Ecology and Hydrology 2005). It is, therefore, necessary to find a fundamental solution to the water shortage problem in Korea.

The easiest method to resolve the water shortage problem is groundwater development or seawater desalination. However, limited groundwater resources and the economic feasibility of seawater desalination and the quality of obtained water are some of the problems associated with the application of the problems associated with these methods. Most countries choose to solve their water shortage problems by means of artificial precipitation (Seo 2001). Desert Research Institute in Reno, Nevada, USA, has implemented a long-term program of cloud seeding, operating 25-30 times a year, spending US $\$ 614,000$ a year over 30 years. In several states in the western USA, programs for precipitation enhancement (rainfall augmentation), hail suppression, and snowpack augmentation using cloud seeding are in the planning or operational stage. Cloud-aerosol interaction and precipitation enhancement experiment in Hyderabad, India, plans to implement artificial rainfall experiments by 2010 , investing 23 billion won for the last 5 years using hygroscopic flares and seeding (Indian Institute of Tropical Meteorology 2009). China too has recently implemented artificial rainfall with silver iodide seeding using cannonballs, rockets, and howitzers.

Thus, cloud seeding is the most common method used worldwide for stimulating rainfall since its first implementation in 1946. However, it is difficult to judge correctly how much of the rainfall after cloud seeding is induced artificially and what part was of natural origin (AMS 1992, 1998; Cotton 1986).

In this study, we present a method for inducing artificial showery rain, by means of ground heating. In this method, a heat source on the ground creates an ascending air current. When this ascending air current overcomes the convective inhibition (CIN) in an unstable atmosphere, showery rain is induced. In spite of almost zero CIN, if updrafts do not exist, convective available potential energy (CAPE) at the upper level is not activated. Therefore, precipitation occurrence is not aided by the CIN value but by the formation, either naturally or artificially, of an updraft from the surface to the CAPE layer.

This happens when the CAPE stored in the atmosphere is activated, accelerating the ascending air current. Therefore, this method can be applied only when there is sufficient CAPE in the atmosphere and the CIN is low, that is, under real latent instability conditions. We examine the temporal and spatial distribution of CAPE and CIN in the upper atmosphere to determine the seasons and geographical regions where artificial rainfall activation is feasible.

Therefore, we examine the climatologic structure in the upper atmosphere in Korea. Firstly, we investigate the climatologic distribution of the environmental parameters and stability index in the upper atmosphere according to regions and then examine the frequency of high instability during the summer, when the instability index is high. Finally, we analyze the rainfall generation probability and degree according to the statistical characteristics of the environmental parameters, the vertical sounding structure of the atmosphere, and the vertical distribution of moisture convergence according to the presence or absence of rainfall in strong real latent instability.

\section{Data}

For the upper layer sounding data, we used rawinsonde data from six stations (Sokcho (SC), Baengnyeongdo (BYD), Osan (OS), Pohang (PH), Gwangju (GJ), and Gosan (GS)) provided by Wyoming University (Fig. 1). The data provided atmospheric pressure and temperature from the ground to the high level layer, dew-point temperature, relative humidity, mixing ratio, and wind speed, as well as environmental parameters (EPs) and stability indices (SIs) calculated using the sounding data. EPs and SIs used in this study are shown in Table 1. The virtual temperaturecorrected CAPE (Doswell and Rasmussen 1994), the normalized CAPE (NCAPE) showing the aspect ratio in the positive area, and the calculation method of the stability indices (lifted index (LI), $\mathrm{K}$ index (KI), and severe weather threat index (SWEAT)) are shown in Table 2. The analysis 


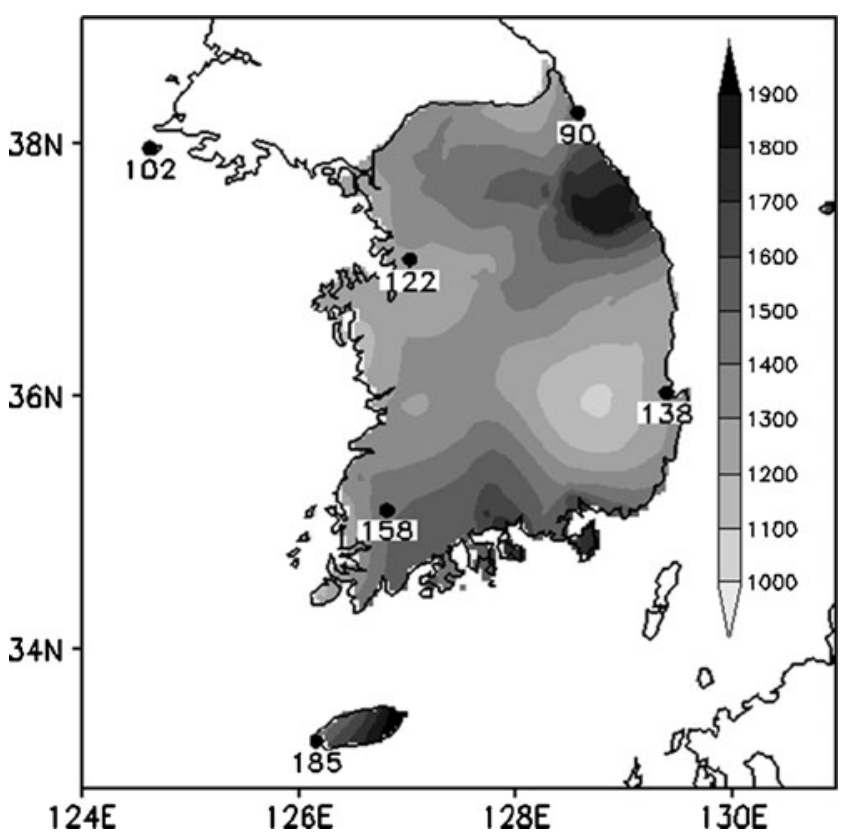

Fig. 1 Six upper observatories (90, Sokcho; 102, Baengnyeongdo; 122, Osan; 138, Pohang; 158, Gwangju; 185, Gosan) were considered in this study. Shaded area shows the annual mean precipitation during 2001-2008

period was from 2001 to 2008 , during which observations were taken twice a day (00:00 and 12:00 coordinated universal time (UTC)). All stations showed an observation frequency of over 300 times a year, except SC in 2001 and 2002. We used the 24-h accumulated AWS data from the Korean Meteorological Administration as precipitation data. The precipitation data for OS station was substituted with data from Suwon, the closest location to OS. For the calculation of moisture convergence, the re-analysis of

Table 1 List of stability indices and environmental parameters

\begin{tabular}{|c|c|c|}
\hline Acronym & Description & Unit \\
\hline LI & Lifted index & - \\
\hline SWEAT & Severe weather threat index & - \\
\hline $\mathrm{KI}$ & $\mathrm{K}$ index & - \\
\hline CAPE & $\begin{array}{l}\text { Convective available potential energy } \\
\text { computed by using virtual temperature }\end{array}$ & $\mathrm{J} / \mathrm{kg}$ \\
\hline NCAPE & Normalized CAPE & $\mathrm{J} / \mathrm{kg} \cdot \mathrm{hPa}$ \\
\hline $\mathrm{CIN}$ & $\begin{array}{l}\text { Convective Inhibition computed by using } \\
\text { virtual temperature }\end{array}$ & $\mathrm{J} / \mathrm{kg}$ \\
\hline LCL & $\begin{array}{l}\text { Lifted condensation level, from an average } \\
\text { of the lowest } 500 \mathrm{~m}\end{array}$ & $\mathrm{~m}$ \\
\hline LFC & $\begin{array}{l}\text { Level of free convection by comparing } \\
\text { temperature between a parcel and the } \\
\text { environment }\end{array}$ & $\mathrm{m}$ \\
\hline FCL & Free convection layer & $\mathrm{hPa}$ or $\mathrm{m}$ \\
\hline EL & $\begin{array}{l}\text { Equilibrium level computed by using virtual } \\
\text { temperature }\end{array}$ & $\mathrm{m}$ \\
\hline PW & Precipitable water for the entire sounding & $\mathrm{mm}$ \\
\hline
\end{tabular}

NCEP/NCAR (temperature, relative humidity, and wind fields) was used.

\section{Climatology of environmental parameters derived from rawinsonde data}

\subsection{Monthly variation of CAPE}

Figure 2 shows the variation of the monthly mean value of CAPE in six stations for the years 2001-2008. The CAPE began to form mostly in May in all stations, gained maximum value in August (except in PH which reached a maximum in July), rapidly decreased in September, and almost nor formed after October. Therefore, the level of free convection (LFC) and equilibrium level (EL) in the South of Korea forms generally between May and October. It shows a little seasonal variation in $\mathrm{PH}, \mathrm{BYD}$, and $\mathrm{SC}$ which are located in a coastal region at relatively high latitude. The seasonal variation of CAPE is related to the seasonal march of Asian monsoon system (Eom et al. 2008). In July and August, when the solar insolation is greatest, deep convection occurs easily. Therefore, we used the mean value of the summer (from June to August (JJA)). The distribution of mean CAPE by stations during JJA was the highest in station GJ, and then dropped in the following order: OS, GS (Jeju), PH, BYD, and SC (Fig. 2).

\subsection{Mean CAPE and CIN at 00:00 and 12:00 UTC}

The distribution of daily mean CAPE at 00:00 and 12:00 UTC in summer (JJA) (Fig. 3) shows that the value at 12:00 UTC was higher than that at 00:00 UTC in all regions, and that the further the inland region is located, the larger is the difference was between the mean CAPE value in the morning and the late evening (GJ and OS). But, there was almost no difference between the values of CIN throughout the day. This means that among the daily soundings (00:00 and 12:00 UTC), the atmospheric condition was more favorable for the generation of deep convection (largest CAPE and Lowest LI) at 12:00 UTC. This result agrees with those of Eom et al. (2008) and Iwasaki and Miki $(2001,2002)$. The water vapor reached maximum value in late evening, due to thermally induced regional circulation (Iwasaki and Miki 2001, 2002). What is unusual is that the highest value of CAPE in the morning (00:00 UTC) was shown not in GJ, which is located furthest inland, but in GS (Jeju) which is located in the lowest latitude.

\subsection{Distribution of CAPE and normalized CAPE}

We extracted only the values which had CAPE at 12:00 UTC, from the soundings of the 8-year period 2001-2008, 
Table 2 Other stability indices and their calculation method

\begin{tabular}{|c|c|}
\hline $\begin{array}{l}\text { Stability } \\
\text { index }\end{array}$ & Equation and description \\
\hline CAPE & $\begin{array}{l}g \int_{Z_{\mathrm{LFC}}}^{Z_{\mathrm{LL}}}\left(\frac{T_{\mathrm{vp}}-T_{\mathrm{ve}}}{T_{\mathrm{ve}}}\right) \mathrm{d} z \\
\left(T_{\mathrm{vp}} \text { is parcel's virtual temperature, } T_{\mathrm{ve}} \text { is ambient air parcel's virtual temperature, } Z_{\mathrm{EL}} \text { is equilibrium level, } Z_{\mathrm{LFC}} \text { is the level of }\right. \\
\text { free convection, and g is gravity acceleration.) }\end{array}$ \\
\hline NCAPE & $\begin{array}{l}\mathrm{NCAPE}=\mathrm{CAPE} / \mathrm{FCL} \\
\left(\mathrm{FCL}=Z_{\mathrm{EL}}-Z_{\mathrm{LFC}}\right)\end{array}$ \\
\hline LI & $\begin{array}{l}T_{500}-T_{\text {parcel }} \\
\left(T_{500} \text { is temperature in Celsius at } 500 \mathrm{mb}, T_{\text {parcel }} \text { is temperature in Celsius at } 500 \mathrm{mb} \text { of a parcel lifted from } 850 \mathrm{mb} \text {.) }\right.\end{array}$ \\
\hline $\mathrm{KI}$ & $\begin{array}{l}K=\left(T_{850}-T_{500}\right)+T \mathrm{~d}_{850}-\left(T_{700}-T \mathrm{~d}_{700}\right) \\
\left(T_{850} \text { is temperature in Celsius at } 850 \mathrm{mb}, T_{500} \text { is temperature in Celsius at } 500 \mathrm{mb}, T \mathrm{~d}_{850} \text { is dew-point in Celsius at } 850 \mathrm{mb}, T_{700}\right. \\
\text { is temperature in Celsius at } 700 \mathrm{mb} \text {.) }\end{array}$ \\
\hline SWEAT & $\begin{array}{l}\mathrm{SWEAT}=12 \times T \mathrm{~d}_{850}+20 \times \mathrm{TERM} 2+2 \times \mathrm{SKT}_{850}+\mathrm{SKT}_{500}+\mathrm{SHEAR} \\
\left(T \mathrm{~d}_{850} \text { is dewpoint in Celsius at } 850 \mathrm{mb} \text {, TERM2 is MAX }(\mathrm{TOTL}-49.0) \text {, TOTL is Total totals index }\right. \\
\left(\mathrm{TOTL}=\left(T_{850}-T_{500}\right)+\left(T \mathrm{~d}_{850}-T_{500}\right)\right), \mathrm{SKT}_{850} \text { is } 850 \mathrm{mb} \text { wind speed in knots, } \mathrm{SKT}_{500} \text { is } 500 \mathrm{mb} \text { wind speed in knots, } \\
\text { SHEAR is } 125 \times\left[\mathrm{SIN}\left(\mathrm{DIR}_{500}-\mathrm{DIR}_{850}\right)+2\right], \mathrm{DIR}_{500} \text { is } 500 \mathrm{mb} \text { wind direction, DIR } \\
850 \text { is } 850 \mathrm{mb} \text { wind direction. })\end{array}$ \\
\hline
\end{tabular}

in order to examine the distribution of the value of CAPE by stations. As a result, the number of soundings extracted was 260 in SC, 256 in BYD, 537 in OS, 356 in PH, 547 in GJ, and 395 in GS (Fig. 4). For comparison, we presented the simplest and easiest interquartile range (IQR, i.e., the central $50 \%$ of values) using a box plot in order to show the degree of distribution. IQR is one of the indices that show the degree of data broadening from the median value (Wilks 1995). The shaded box represents $50 \%$ of the data, the median value is shown by a solid line, and the mean value is shown by a dotted line. The top and the bottom of the box represent $\pm 25 \%$. The top and bottom of the vertical line represent the value included in the acceptable range. Although the CAPE value (50\% range) was the highest in GJ, the general distribution in OS, GJ, and GS seemed similar. The distribution of the median value was similar in GJ, OS and GS (GJ>OS $>$ GS), superior to the top of shaded box 50\% in BYD and SC, and inter alias, the value in GJ was the highest with $378.05 \mathrm{~J} / \mathrm{kg}$ (Fig. 4a). The distribution of the mean value followed a similar pattern, in descending order of GJ, OS, and GS. The CAPE value was largest in GJ which is different with the result of Eom et al.
(2008). They investigated that the CAPE value for OS is largest.

Figure $4 \mathrm{~b}$ shows the distribution of (NCAPE) by stations. NCAPE, which is an important criterion to evaluate the probability of development of convective clouds, shows well how CAPE changes according to the depth of the free convective layer (FCL) (Zipser and Lemone 1980; Lucas et al. 1994; Blanchard 1998). Here, as well as in Fig. 4a, the mean values for three stations, $\mathrm{OS}$, GJ, and $\mathrm{GS}$, were $0.64,0.72$, and $0.68 \mathrm{~J} / \mathrm{kg} \cdot \mathrm{hPa}$, respectively. Although the value in GJ was the highest, the value in GS was higher than OS while the CAPE in OS was higher than in GS. Looking at the distribution of IQR by stations, the range in GJ was the largest with $0.21-$ $1.86 \mathrm{~J} / \mathrm{kg} \cdot \mathrm{hPa}$, and those of OS and GS were $0.23-1.41$ and $0.26-1.45 \mathrm{~J} / \mathrm{kg} \cdot \mathrm{hPa}$, respectively. The range in SC was the smallest with $0.08-0.52 \mathrm{~J} / \mathrm{kg} \cdot \mathrm{hPa}$, and the median value was the lowest.

Figure 5 shows the distribution plot representing the relation between the lifted index and the CAPE and NCAPE in the six stations. In Fig. 5a, the CAPE value was limited to $1,000-3,000 \mathrm{~J} / \mathrm{kg}$, since statistically, several
Fig. 2 Monthly variations of daily mean CAPE $(\mathrm{J} / \mathrm{kg})$ at six stations at 12:00 UTC during 2001-2008

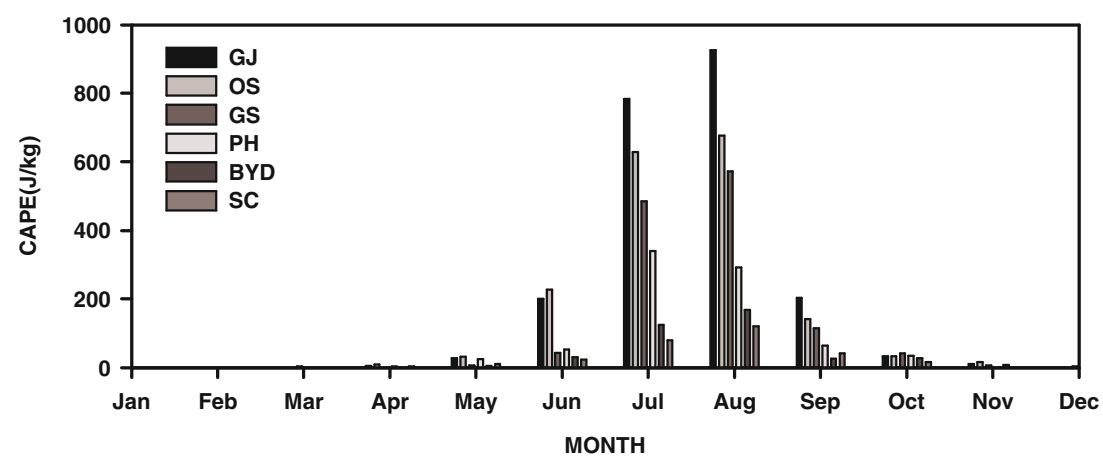




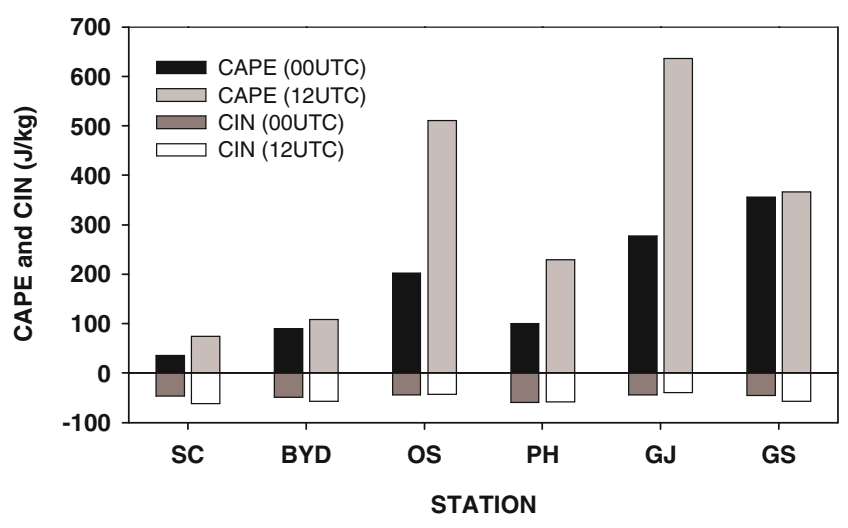

Fig. 3 Mean CAPE and CIN values at 00:00 and 12:00 UTC at six stations in JJA during 2001-2008

extreme values beyond this range would be insignificant (Blanchard 1998). In this range, the coefficient of determination $R^{2}$ (correlation coefficient $R$ ) was $0.29(-0.54)$. Such value may be interpreted as a fraction of the entire variation explained by the least squares regression line. Therefore, almost $70 \%$ of the variation of the CAPE may be explained as resulting not from instability but from other factors (i.e., $\Delta T_{\mathrm{v}}$ ). Figure $5 \mathrm{a}$ shows that for $\mathrm{CAPE}=2,000 \mathrm{~J} / \mathrm{kg}$, the range of LI was from -2.5 to -7.0 , which suggests there was only moderate correlation between CAPE (integrated parcel buoyancy) and LI (single-level virtual temperature)

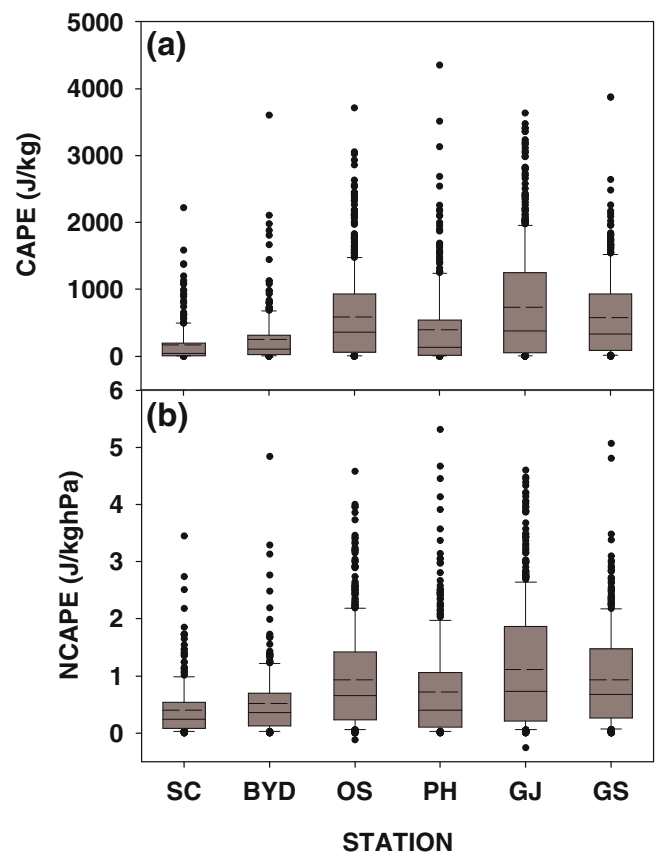

Fig. 4 Box plot showing distribution of CAPE and NCAPE for six sounding sites in JJA during 2001-2008. The shaded box encloses $50 \%$ of the data, with the median value of the variable displayed as a horizontal line. The top and bottom of the box mark the limits of $25 \%$ of the variable population. The lines extending from the top and bottom of each box mark the minimum and maximum values that fall within an acceptable range and means that the variation of CAPE was influenced by the unstable atmosphere as well as other meteorological factors such as the FCL.

In Fig. 5b, the coefficient of determination $R^{2}$ (correlation coefficient $R$ ) with relation to NCAPE with LI was $0.55(-0.74)$, representing a much higher relation than with CAPE. This supports the assumption that it is a better indicator than CAPE for the mean buoyancy.

\subsection{Frequency of latent instability}

Figure 6 shows the bar graph representing the mean frequency of latent instability by types, in summer, for 8 years in all the stations. The station with the most days of real latent instability was GJ, located inland, with 51.9 days. After GJ, OS ranked second with 51.3 days. In other regions, number of days with no latent instability was high. Like the frequency of high instability values analyzed above, the further inland the region was, the stronger the instability was. What is unusual is that the number of days of pseudo-latent instability was 15 20, representing similar days by regions. This means days where positive energy existed, but the negative energy was higher than the positive energy and consequently convection could not occur, which represents about $20 \%$ of the summer.

\subsection{Distribution of LCL, LFC, EL, and depth of FCL}

Figure 7 shows the comparison of the altitude distributions of EL, LFC, and lifted condensation level (LCL), and the depth of the FCL according to stations, using IQR. The order was GS, GJ and OS for the distribution of EL; GJ, OS, and GS for LFC distribution; GJ, GS, and OS for LCL distribution; and GJ, GS, and OS for the depth of the FCL. The range of IQR, in $\mathrm{PH}$ and $\mathrm{SC}$ was the largest, which meant the biggest variation.

The difference in altitude between the EL and LFC is an indication of the amount of CAPE; stations showing a big difference between EL and LFC (GJ, GS, and OS) had high CAPE values. In this case, there is a high probability of convection, that is, air ascending in a natural or artificial way, where it could easily be saturated. In addition, the lower the altitude of LCL was, the lower the cloud base appeared, which is related to high relative humidity in the boundary layer and the probability of tornado generation (Rasmussen and Blanchard 1998; Craven et al. 2002; Eom et al. 2008). As shown in Fig. 7d, the vertical depth of cloud formation in GJ, OS, and GS is large.

3.6 $925 \mathrm{hPa}$ and vertical distribution of daily mean dew-point depression

Figure 8 shows the time series representing the daily mean dew-point depression at $925 \mathrm{hPa}$ by stations. $925 \mathrm{hPa}$ is an 
Fig. 5 Distribution of a CAPE and $\mathbf{b}$ NCAPE versus LI for six stations. The range of CAPE has been limited to fall between 1,000 and $3,000 \mathrm{~J} / \mathrm{kg}$

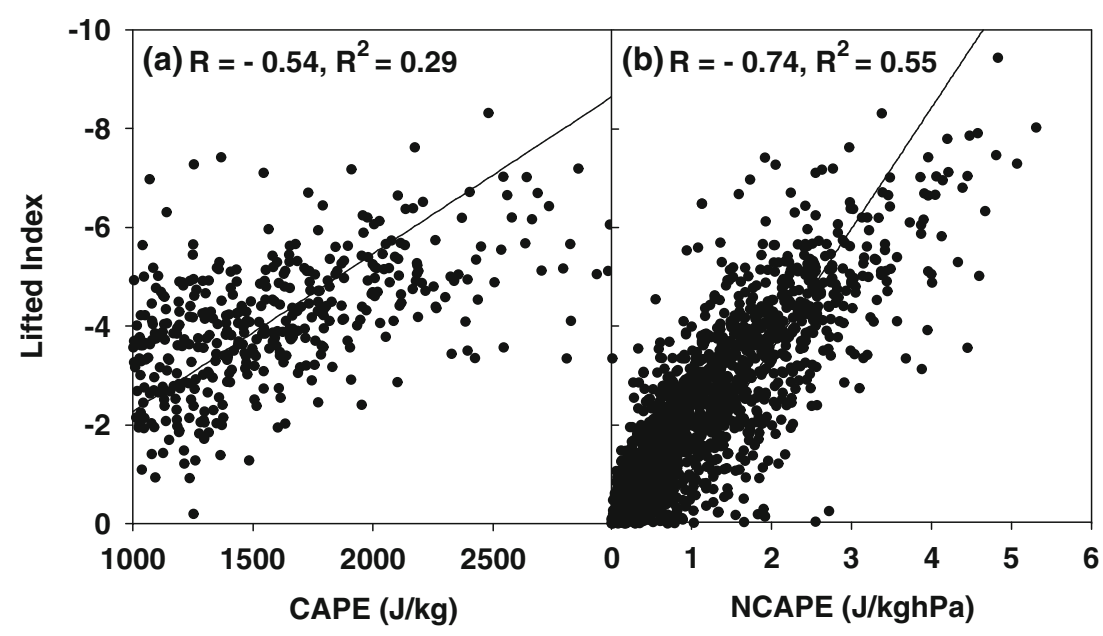

altitude around the planet boundary layer where there is almost no friction force and the influence of terrain features is minimal. The dew-point depression is equal to the difference between the temperature and the dew-point temperature, which is a good indicator of the humidity and the relative amount of moisture content. To show the general trends, a negative exponential smoother was used. This is a local smoothing technique using polynomial regression and weights computed from the Gaussian density function. The solid line refers to the annual mean value. The dew-point depression tended to be high in spring and autumn in all regions and low in summer in all stations, which reflected well the seasonal characteristics. In comparing the various stations, the dew-point depression in summer as well as the annual mean of it was lowest in GJ. This clearly shows that the humidity year round in this region was the highest compared with the other regions and the moisture content was much existed. BYD was the driest region in spring and autumn, marking a big difference to the results in summer. The annual variation of dew-point depression in PH was the lowest. BYD, OS, GJ, and GS were dry in spring and autumn, while SC and $\mathrm{PH}$ tended to be much drier during winter. Apart from the summer

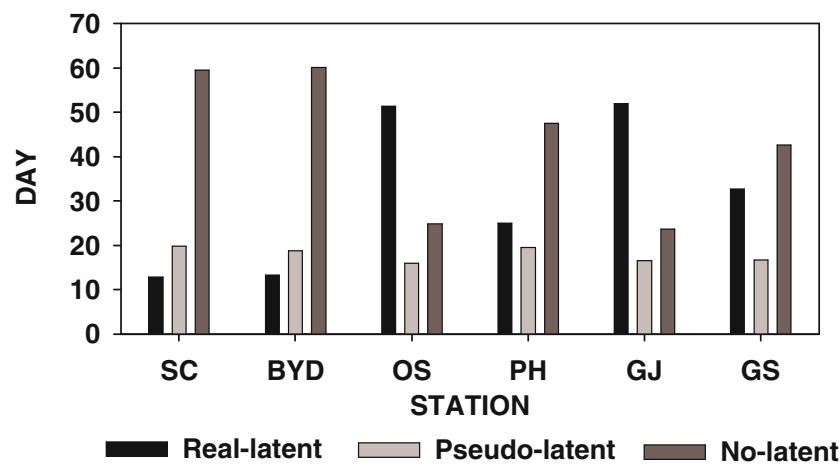

Fig. 6 As in Fig. 3 but for mean latent instability days season, the variation of dew-point depression was high in all stations.

Figure 9 shows the distribution of the dew-point depression deviation from the lower layer to the upper layer $(925-400 \mathrm{hPa})$ as in Fig. 8. The humidity in the lower layer during summer in OS and GJ was high, and the water vapor in the lower layer was more abundant than in other regions. The reason why the humidity was higher in spring in SC, with more water vapor than in other regions, was deemed to be the influence of the northeasterly air flow due to the Okhotsk Sea high-pressure system. On the other hand, there were some unusual results: the humidity in the middle and upper layers was lower in GJ, while in GS the humidity in the lower layer was lower in summer, and in OS the humidity in the middle and upper layers in winter was higher than in other regions.

\section{Frequency of index extremes}

\subsection{Climatological frequency of instability index extremes}

Figure 10 represents the mean frequency on a day of strong instability in summer by stations on the basis of severe weather thresholds during the analysis period. The thresholds might be different for different regions, e.g., CAPE thresholds are lower in Europe than in the USA (Brooks et al. 2003). The four threshold levels were based on the values selected in the previous studies as follows: LI below -6 represents "very unstable." Johns et al. (1993) states that $75 \%$ of tornadoes occur under such conditions. The $1,800 \mathrm{~J} / \mathrm{kg}$ threshold of the CAPE was based on the results of the Rasmussen and Blanchard (1998) study which confirmed that all storms occurred when CAPE $>1,820 \mathrm{~J} / \mathrm{kg}$. The value of $\mathrm{KI}>35$ represents a very high probability of thunderstorms generation with risk of heavy rain and flood (80-90\%) (Giordano 1994), and the 300 threshold of 
Fig. 7 As in Fig. 4 but for EL, LFC, LCL, and depth of FCL levels in JJA. The outliers are excluded
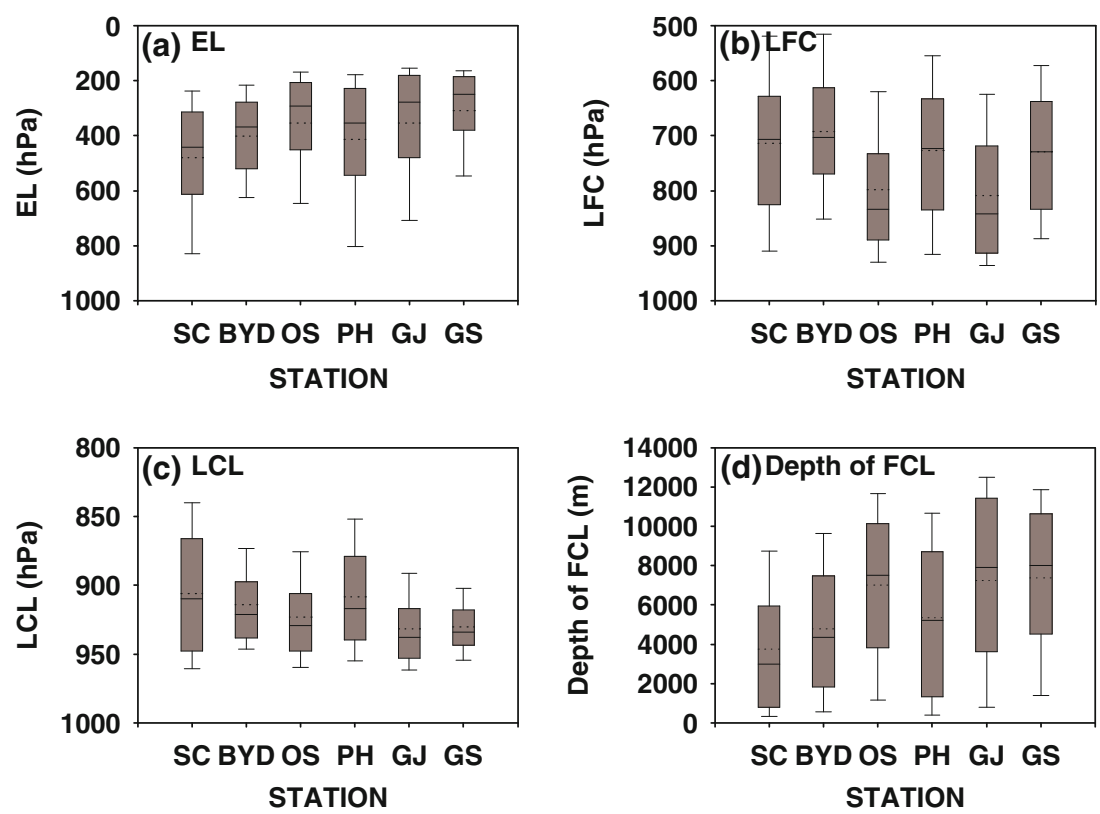

SWEAT is proven as a value of severe thunderstorms in the study of Miller (1972).

The result shows that the frequency of days of instability in summer was the highest in GJ followed by $\mathrm{GS}$ and $\mathrm{OS}$, and then $\mathrm{PH}, \mathrm{BYD}$, and $\mathrm{SC}$, in that order. The value of LI below -6 was rarely seen (Fig. 10a), with 2.5 days in GJ, 1 day in OS, GS and PH and hardly a day in BYD, and SC, on average. That means that high ground temperature and humidity caused the value of LI to decrease (Derubertis 2006). The frequency of the days with CAPE over $1,800 \mathrm{~J} / \mathrm{kg}$ was clearly the highest in GJ (Fig. 10b), which meant the ground temperature and humidity there were the highest of the six stations. $\mathrm{KI}$ is sensitive to the water vapor in the upper troposphere (Derubertis 2006). The frequency in GJ, GS, and OS was about 15 days, which meant that water vapor was abundant over the middle layer. Since SWEAT among the four factors is calculated in comparison with wind speed and wind shear in the upper layer and the temperature on the ground and in the upper layer, this
Fig. 8 Time series of daily mean dew-point depression at $925 \mathrm{hPa}$ and 12:00 UTC during 2001-2008. Solid line shows the yearly mean value
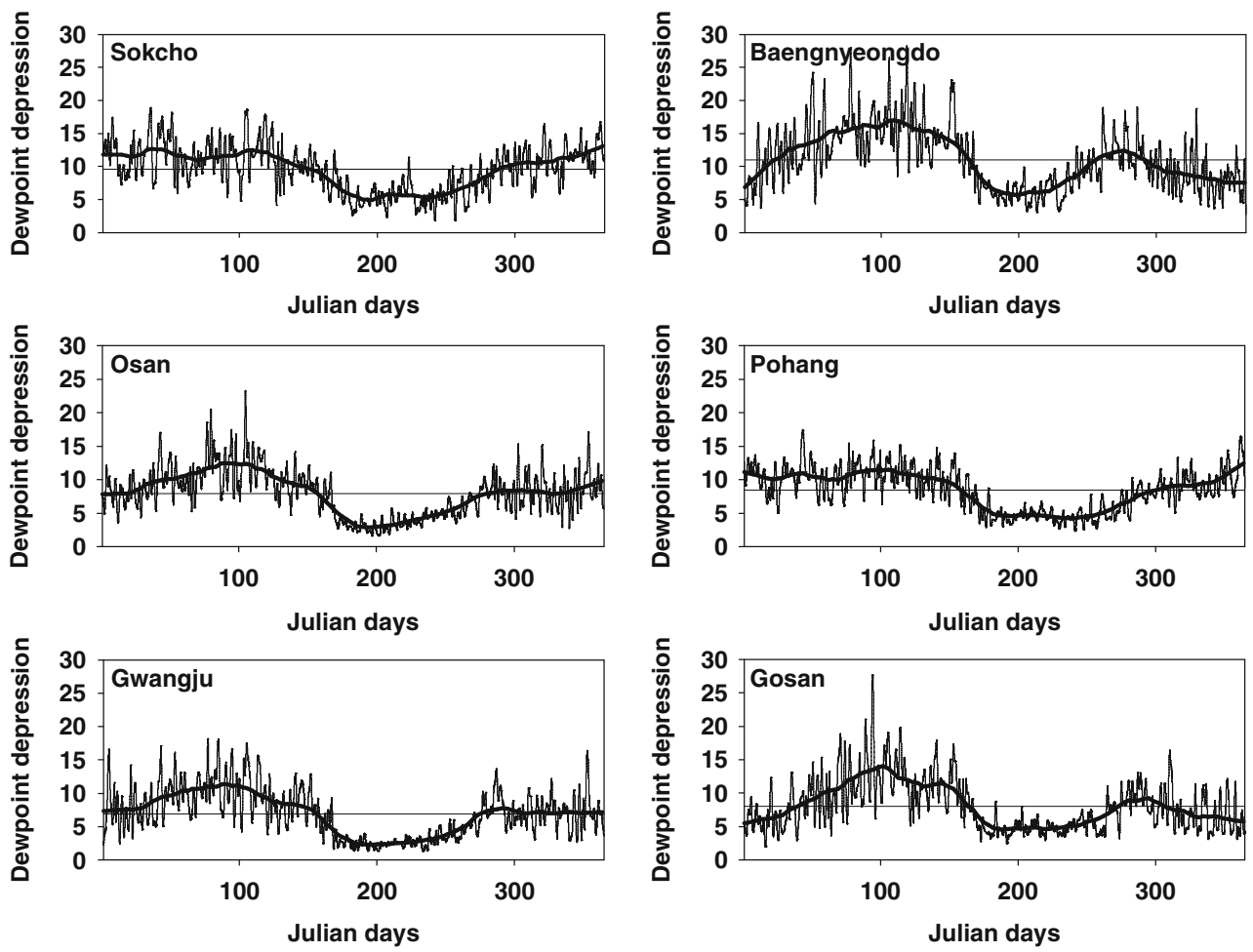
(a) Sokcho

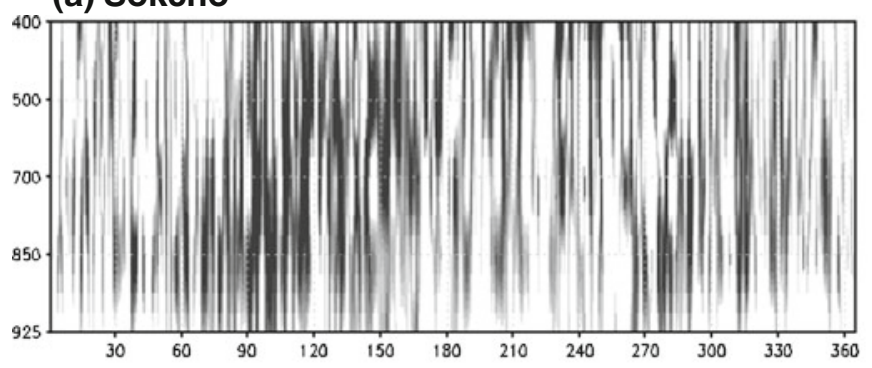

(c) Osan

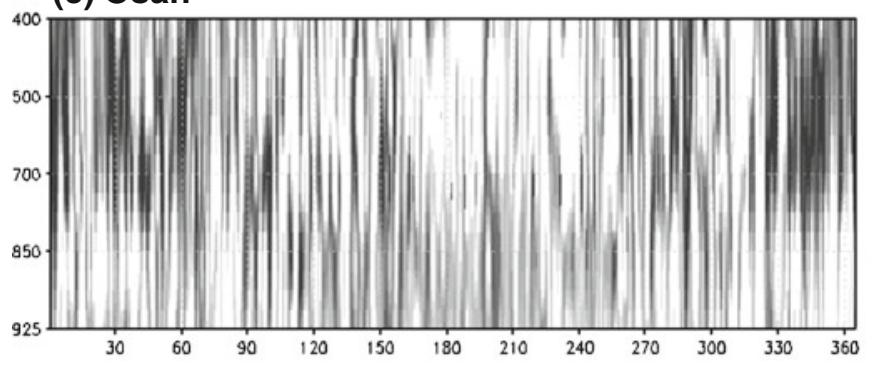

(e) Gwangju

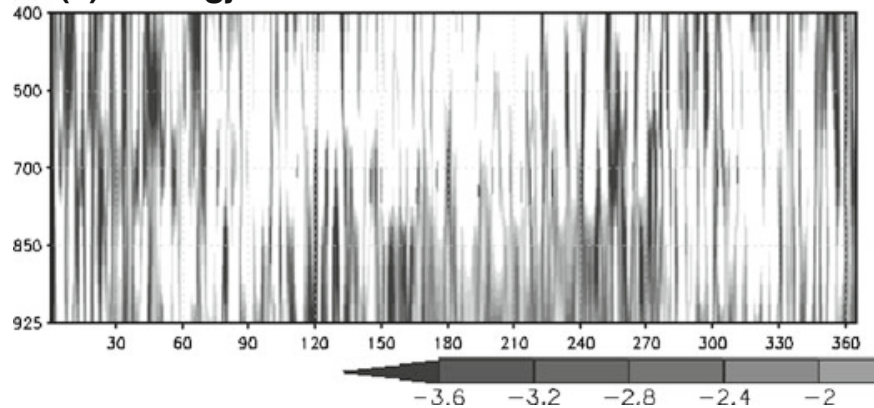

(b) Baengnyeongdo

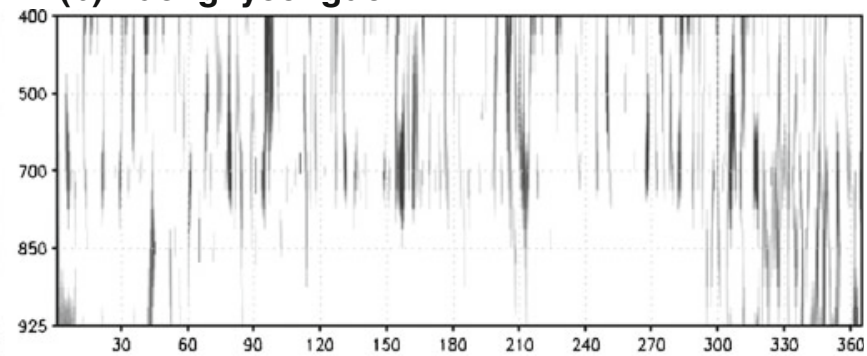

(d) Pohang

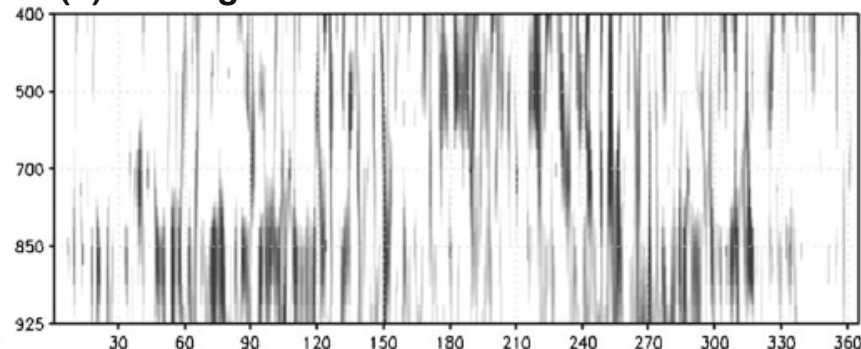

(f) Gosan

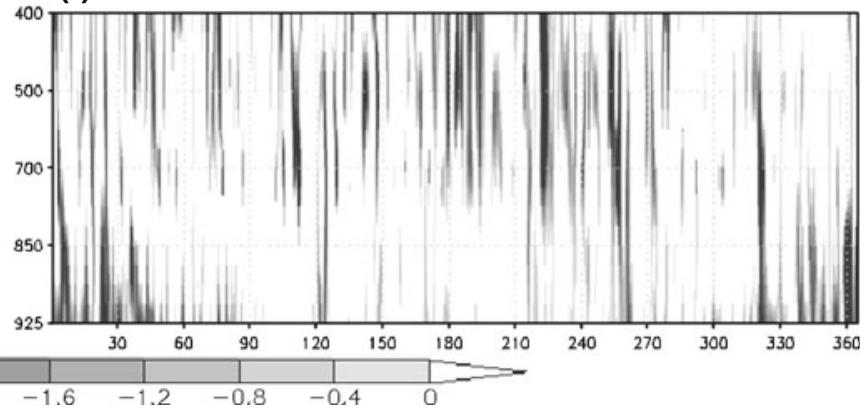

Fig. 9 Vertical distribution of daily mean dew-point depression deviation during 2001-2008. Negative deviations of dew-point depression have been shaded

Fig. 10 Average number of days when stability index thresholds are exceeded in summer (JJA): a, LI <-6, b, $\mathrm{CAPE}>1,800 \mathrm{~J} / \mathrm{kg}, \mathbf{c}, \mathrm{KI}>35$, and $\mathbf{d}$, SWEAT $>300$
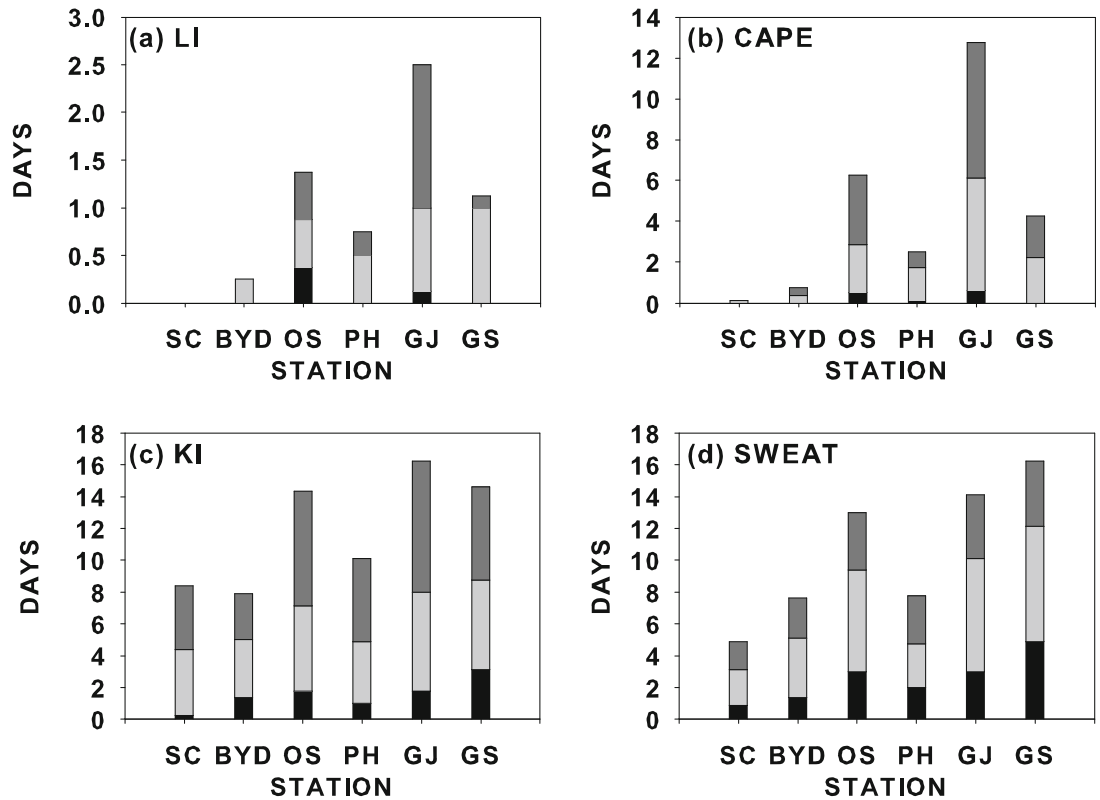

JUNE $\rightleftharpoons$ JULY $\rightleftharpoons$ AUGUST 
factor well represents the convergence of different air masses and the position of the jet stream (Derubertis 2006). The frequency was highest in GS, which we believe is a result of its geographical location, being the most southerly and exposed to the southward movement of the subtropical jet stream.

As for the monthly frequency in summer, LI, CAPE, and KI were shown more unstable in August than in July for GJ and OS, while more so in July than in August for GS and PH. In June, there was almost no extreme frequency. For SWEAT, the extreme frequency was highest in July in all stations, but was evenly scattered in June, July, and August.
4.2 Frequency of days with CAPE $>3,000 \mathrm{~J} / \mathrm{kg}$

Table 3 refers to the frequency of days with CAPE> $3,000 \mathrm{~J} / \mathrm{kg}$ at 12:00 UTC by stations for the analysis period. The selected days refer to the real latent instability, representing very unstable atmospheric conditions, with no day over $3,000 \mathrm{~J} / \mathrm{kg}$ in $\mathrm{SC}$, and 22 days in GJ, the highest occurrence. For most days, the atmospheric conditions were favorable for the occurrence of deep convection, but the number of days of actual precipitation was under $40 \%$, and even then, the precipitation was low.

Despite CIN is zero, there are cases without precipitation (one case in PH and GJ, respectively). There is a layer in

Table 3 Days of extreme CAPE per stations and that day's value of CAPE, NCAPE, CIN, LCL, LFC, EL, PW, and rainfall

\begin{tabular}{|c|c|c|c|c|c|c|c|c|c|c|c|}
\hline Station number & Year & Month & Day & CAPE & NCAPE & $\mathrm{CIN}$ & LCL & LFC & EL & PW & Rainfall \\
\hline Baengnyeongdo & 2002 & 7 & 14 & 4,111 & 4.8 & -6.0 & 739 & 880 & 12,882 & 34.8 & 0.0 \\
\hline \multirow[t]{5}{*}{ Osan } & 2002 & 9 & 3 & 3,274 & 3.9 & -3.4 & 524 & 758 & 12,997 & 50.8 & 0.0 \\
\hline & 2004 & 8 & 10 & 3,323 & 4.0 & -17.9 & 620 & 1,080 & 13,253 & 47.8 & 0.0 \\
\hline & 2005 & 6 & 30 & 4,126 & 4.6 & 0.0 & 455 & 487 & 13,705 & 41.0 & 4.0 \\
\hline & 2007 & 8 & 2 & 3,392 & 4.0 & -4.9 & 591 & 957 & 13,905 & 51.9 & 0.3 \\
\hline & 2007 & 8 & 9 & 3,314 & 3.7 & 0.0 & 395 & 462 & 13,917 & 59.5 & 14.0 \\
\hline \multirow[t]{3}{*}{ Pohang } & 2001 & 7 & 2 & 3,877 & 4.7 & -6.2 & 930 & 1,131 & 14,174 & 55.3 & 1.0 \\
\hline & 2002 & 7 & 29 & 3,493 & 4.1 & -17.2 & 521 & 1,092 & 14,248 & 57.3 & 0.0 \\
\hline & 2002 & 7 & 31 & 4,779 & 5.3 & 0.0 & 632 & 637 & 14,760 & 57.4 & 0.0 \\
\hline \multirow[t]{22}{*}{ Gwangju } & 2001 & 7 & 24 & 3,451 & 4.0 & -0.2 & 614 & 627 & 13,345 & 56.6 & 0.0 \\
\hline & 2001 & 7 & 29 & 3,066 & 3.5 & -2.2 & 649 & 743 & 13,827 & 53.1 & 0.0 \\
\hline & 2001 & 7 & 30 & 3,661 & 4.1 & -0.3 & 532 & 596 & 14,235 & 65.3 & 2.3 \\
\hline & 2001 & 7 & 31 & 3,567 & 4.1 & -1.9 & 624 & 735 & 14,230 & 61.7 & 8.6 \\
\hline & 2001 & 8 & 1 & 3,467 & 4.1 & -1.9 & 591 & 696 & 13,733 & 65.1 & 0.0 \\
\hline & 2001 & 8 & 16 & 3,288 & 4.0 & -11.6 & 799 & 1,017 & 13,693 & 57.2 & 0.0 \\
\hline & 2001 & 8 & 17 & 3,756 & 4.3 & -2.8 & 782 & 854 & 13,909 & 48.2 & 0.0 \\
\hline & 2002 & 8 & 28 & 3,984 & 4.5 & -1.4 & 493 & 668 & 14,572 & 63.4 & 5.5 \\
\hline & 2002 & 9 & 3 & 3,600 & 4.2 & -8.3 & 534 & 843 & 13,322 & 46.1 & 0.0 \\
\hline & 2004 & 7 & 23 & 3,371 & 4.6 & -57.7 & 977 & 1,896 & 13,984 & 46.5 & 0.0 \\
\hline & 2005 & 9 & 1 & 3,046 & 3.5 & 0.0 & 325 & 508 & 13,089 & 55.7 & 53.5 \\
\hline & 2006 & 8 & 3 & 3,725 & 4.4 & -12.1 & 609 & 951 & 14,322 & 58.4 & 0.0 \\
\hline & 2006 & 8 & 14 & 3,172 & 3.6 & -2.1 & 511 & 800 & 14,339 & 62.1 & 0.0 \\
\hline & 2007 & 7 & 24 & 3,073 & 3.4 & 0.0 & 354 & 428 & 13,959 & 66.1 & 0.0 \\
\hline & 2007 & 7 & 25 & 3,094 & 3.5 & -0.7 & 518 & 615 & 13,823 & 58.4 & 0.0 \\
\hline & 2007 & 7 & 29 & 3,409 & 4.5 & -32.7 & 735 & 1,242 & 13,152 & 54.2 & 0.0 \\
\hline & 2007 & 8 & 2 & 3,346 & 3.9 & -11.2 & 732 & 995 & 14,459 & 56.2 & 0.0 \\
\hline & 2007 & 8 & 3 & 3,468 & 3.9 & -0.2 & 523 & 603 & 14,535 & 65.0 & 0.0 \\
\hline & 2007 & 8 & 8 & 3,670 & 4.2 & -0.2 & 434 & 568 & 14,030 & 67.2 & 22.5 \\
\hline & 2007 & 8 & 24 & 3,402 & 3.9 & -4.0 & 622 & 764 & 13,798 & 50.1 & 0.0 \\
\hline & 2007 & 8 & 28 & 3,743 & 4.2 & 0.0 & 314 & 350 & 13,697 & 63.5 & 20.5 \\
\hline & 2008 & 7 & 13 & 3,115 & 3.7 & -6.4 & 606 & 892 & 13,605 & 63.2 & 3.0 \\
\hline \multirow[t]{2}{*}{ Gosan } & 2001 & 7 & 30 & 4,182 & 5.1 & -59.9 & 651 & 1,120 & 14,649 & 69.3 & 3.0 \\
\hline & 2001 & 8 & 1 & 4,173 & 4.8 & 0.0 & 474 & 600 & 13,984 & 65.0 & 0.3 \\
\hline
\end{tabular}


the atmosphere that has extreme CAPE. However the parcel does not reach or begin rising to that level, the most significant convection that occurs in the FCL would not be realized. This can occur for numerous reasons. Primarily, it is the result of a cap or CIN. Processes that can erode this inhibition are heating of the Earth's surface and forcing.

\section{Characteristics of precipitation according to CAPE and CIN}

5.1 Environmental parameters for presence and absence of precipitation

Figure 11 refers to the distribution of LCL, LFC and FCL depth according to the presence or absence of precipitation for whole days when positive energy occurred (Fig. 11a-c). To show the general trends, an exponential smoother was applied as in Fig. 8. As the value of CAPE increased, the altitude thereof (LCL and LFC) tended to decrease, as shown in Fig. 11a, b, while the depth of FCL tended to exponentially increase as shown in Fig. 11c. It was also noted that the LCL and LFC formed at a lower altitude on the days that precipitation occurred than on days of no precipitation, and that the depth of the FCL was larger on precipitation days. Therefore, the value of CAPE was
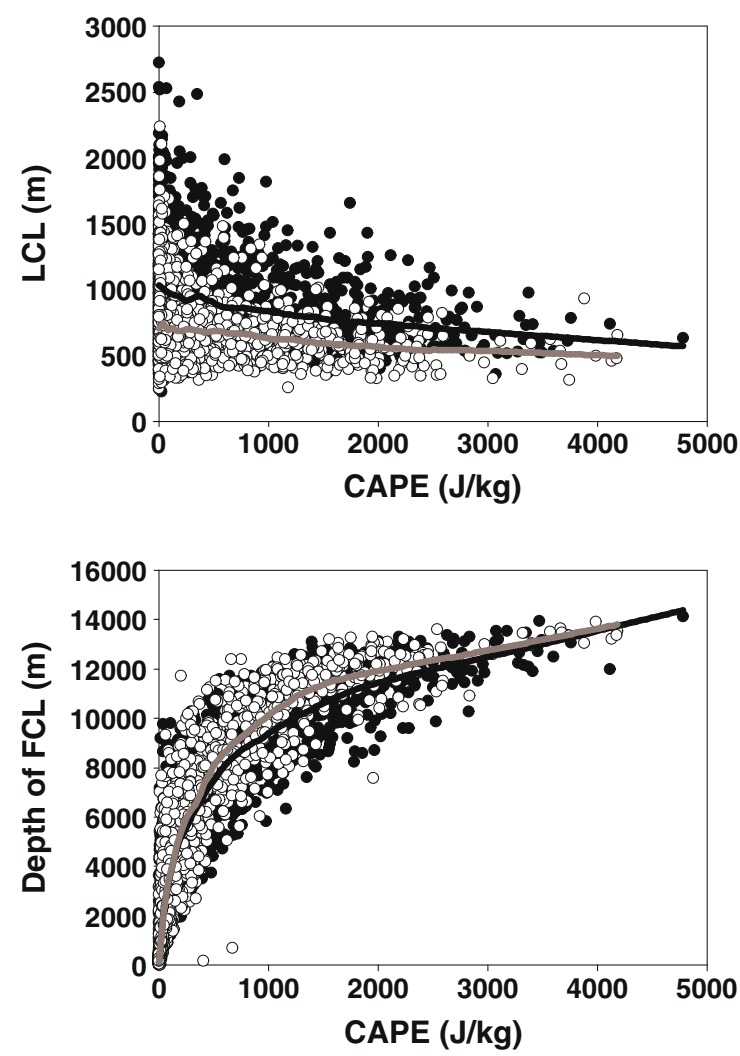

increased. However, although the altitude of LCL and FCL was low and the depth of FCL was large, there existed the days of no precipitation.

On days with CAPE over $3,000 \mathrm{~J} / \mathrm{kg}$ as shown above (Table 3), when precipitation occurred, a little precipitation was estimated on most days to be generated from stratiform clouds, and was positioned within or around the high pressure on days of no precipitation (not shown). This means that the precipitation was generated in convective clouds by strong ascending air currents when the atmosphere was unstable, but weak ascending air current was not able to cause condensation in the air parcel (the convective cloud was not created), so precipitation could not occur. If the CAPE is large and the ascending air current is enough to reach the LFC, the condition becomes favorable for the creation of deep, moist convection (Schultz et al. 2000). Therefore, even though the atmospheric conditions are very unstable, if the ascending air current does not exist or is weak, precipitation will not occur.

\subsection{Distribution of CAPE and CIN in the presence and absence of precipitation}

Figure 12a shows the IQR of CAPE and the CIN values in the presence and absence of precipitation. The CAPE values show similar distributions, regardless of the presence

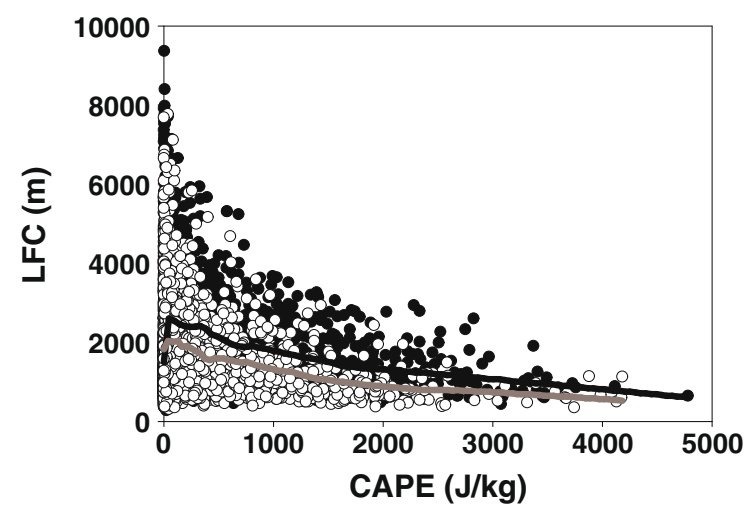

- No-precipitation

- Precipitation

Fig. 11 Variation of LCL, LFC, and depth of FCL according to CAPE during 2001-2008. Black and dark gray solid lines show the exponential smoothing values in the case of non-precipitation and precipitation occurrence, respectively 
or absence of precipitation. However, in the case of CIN, the distributions of values in the range corresponding to $50 \%$ and the median values are observed to be closer to zero on days when precipitation occurred. Figure $12 \mathrm{~b}$ shows the empirical cumulative probability distributions of CAPE and CIN plotted using the same values. At CAPE lower than $3,000 \mathrm{~J} / \mathrm{kg}$, lower CAPE values were observed on days of precipitation; for CAPE higher than $3,000 \mathrm{~J} / \mathrm{kg}$, higher CAPE values were observed on days of no precipitation. However, on an average, the differences were not discernable. On the contrary, in the case of CIN, the frequencies of small values (small negative buoyancy) were higher on days of precipitation than on days of no precipitation. This implies that, in summer, regardless of the magnitude of CAPE, the smaller the CIN, the higher is the probability of occurrence of precipitation.

To examine the effects of CAPE and CIN on precipitation in greater detail, the distributions of CAPE and CIN in the presence and the absence of precipitation and with CAPE greater than $1,800 \mathrm{~J} / \mathrm{kg}$ in summer (June-August) were analyzed (Fig. 12c). In the case of days with precipitation, the CIN values were distributed close to zero, regardless of the CAPE values. In the three cases (triangles shaded in dark gray in Fig. 12c), the CIN was less than $-50 \mathrm{~J} / \mathrm{kg}$; thus, convection in the lower atmosphere was strongly suppressed. However, it is considered that precipitation occurred because of the presence of updrafts that were strong enough to overcome $\mathrm{CIN}$ and activate the CAPE immanent in the upper atmosphere.

However, there are many cases where precipitation does not occur in spite of a high CAPE (greater than $3,000 \mathrm{~J} / \mathrm{kg}$ ) and a low or almost zero CIN. This is because the occurrence of precipitation is associated not only with CIN but also with other environmental factors. Primarily, the existence of updrafts near the earth's surface that induce the air in the lower atmosphere to ascend and activate CAPE in the upper atmosphere causes precipitation.

Forcing mechanisms that may trigger these updrafts include any atmospheric phenomenon that creates some sort of evacuation of mass in the upper levels of the atmosphere, or a surplus of mass in the lower levels of the (a)

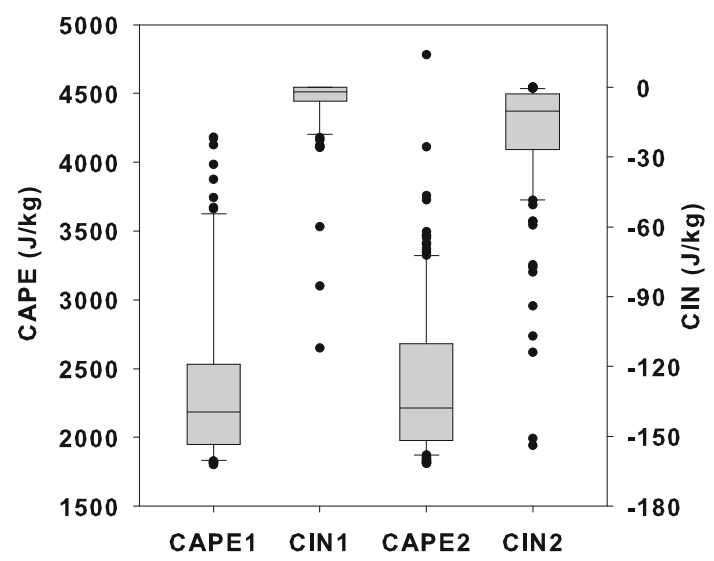

(b)

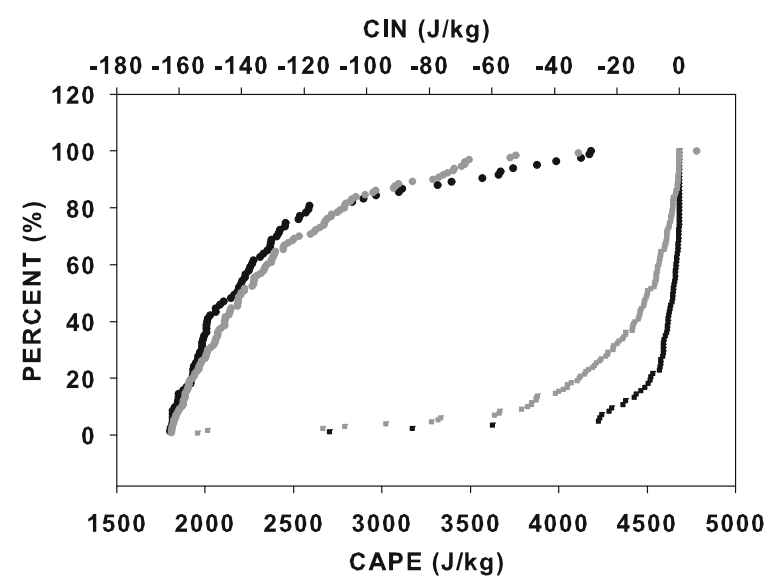

(c)

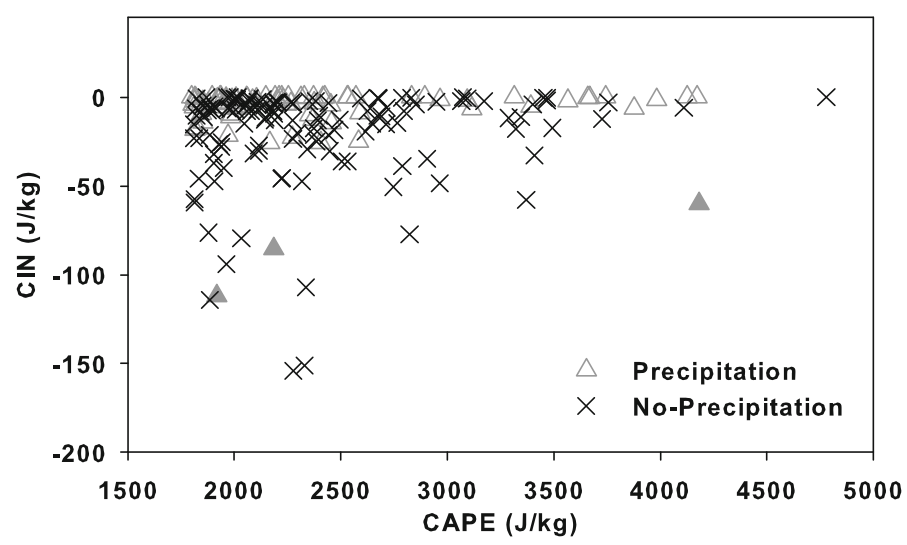

Fig. 12 Distribution of CAPE and CIN in the presence and absence of precipitation during JJA. a IQR of CAPE and CIN, b empirical cumulative density function of CAPE and CIN. Black (dark gray) dot represents the CAPE and CIN in the presence (absence) of precipitation. c Scatter plot of CAPE and CIN above CAPE with $1,800 \mathrm{~J} / \mathrm{kg}$ 
Table 4 Hypothetical environmental parameters in Skew-T log-P diagram

\begin{tabular}{ll}
\hline Environmental parameters & Values \\
\hline Surface temperature & $293 \mathrm{~K}$ \\
Surface dew-point temperature & $292 \mathrm{~K}$ \\
LCL & $970 \mathrm{hPa}$ \\
LFC & $700 \mathrm{hPa}$ \\
Convective temperature & $303 \mathrm{~K}$ \\
Mixing ratio in $292 \mathrm{~K}$ at $1,000 \mathrm{hPa}$ & $14.0 \mathrm{~g} / \mathrm{kg}$ \\
EL with mixing ratio $(0.5 \mathrm{~g} / \mathrm{kg})$ & $150 \mathrm{hPa}$ \\
\hline
\end{tabular}

atmosphere, which lead to upper level divergence or lower level convergence, respectively. Vertically upward motion often follows. Specifically, a cold front, sea/lake breeze, outflow boundary, or forcing through vorticity dynamics of the atmosphere such as with troughs, both shortwave and longwave. Jet streak dynamics through the imbalance of coriolis and pressure gradient forces, causing subgeostrophic and supergeostrophic flows, can also create vertically upward motion (Stensrud 1996).

Other than these natural forcing mechanisms, theoretically, updrafts can be triggered on the ground by heating the air on the surface, through ground heating, to temperatures greater than the convection temperature. In this study, we attempt to prove that, in theory artificial showery rainfall can be induced in atmospheric states of real latent instability by means of artificial ground heating.

5.3 Rough estimation of precipitation induced by artificial updrafts

If the air near the earth's surface is heated to a temperature greater than the convection temperature through artificial ground heating, it will attain positive buoyancy and ascend. If, in a given atmospheric state, the strength of updrafts is known then the amount of precipitation can be approxi- mated (Byun and Cho 1981). For the atmospheric state listed in Table 4, the ascent velocity can be calculated using Eq. 1 (Belentsova 1966).

$W_{\mathrm{m}}^{2} / 2=\eta C_{\mathrm{p}} \Delta T_{\mathrm{m}}\left(\log P_{\mathrm{c}}-\log P_{\mathrm{m}}\right)$

where, $\eta=\left(T_{\mathrm{ccl}}-T_{\mathrm{m}}\right) / T_{\mathrm{ccl}}\left(T_{\mathrm{ccl}}\right.$ may be changed to $\left.T_{\mathrm{lcl}}\right), C_{\mathrm{p}}$ (constant pressure specific heat of dry air) $=1,004 \mathrm{~J} / \mathrm{K} \cdot \mathrm{Kg}$, $\Delta T_{\mathrm{m}}$ is the maximum temperature difference between the air ascending moist-adiabatically in CCL and the surrounding air, $P_{\mathrm{c}}$ is the atmospheric pressure in $\mathrm{CCL}, P_{\mathrm{m}}$ is the atmospheric pressure at the altitude where $\Delta T_{\mathrm{m}}$ appears, $T_{\mathrm{m}}$ is the temperature at the altitude where $\Delta T_{\mathrm{m}}$ appears. If $\Delta T_{\mathrm{m}}$ is given as $11 \mathrm{~K}, P_{\mathrm{m}}$ as $500 \mathrm{hPa}, T_{\mathrm{m}}$ as $270 \mathrm{~K}, P_{\mathrm{c}}$ as $720 \mathrm{hPa}$ and $T_{\mathrm{lcl}}$ as $296 \mathrm{~K}$ and if there exist updrafts sufficient for going up to $700 \mathrm{hPa}$, then the speed of updrafts would be $17.5 \mathrm{~m} / \mathrm{s}$. Therefore, theoretically, approximately $1,119 \mathrm{~mm}$ of precipitation can occur if updrafts of $17.5 \mathrm{~m} / \mathrm{s}$ persist for $1 \mathrm{~h}$.

\subsection{Precipitation formation factors in extreme CAPE}

We analyzed the vertical distribution of mean moisture convergence and omega in GJ in order to investigate the characteristics on the day of precipitation among the cases of extreme CAPE shown in Table 3. Among 22 cases in total, there were 7 days of precipitation and 15 days of no precipitation, taking an average of 8 atmospheric levels in total $(1,000,925,850,700,600,500,400$, and $300 \mathrm{hPa})$ (Fig. 13). The solid black line represents the mean moisture convergence of precipitation days and the solid dark gray line represents one of no precipitation days. The mean values had a $95 \%$ confidence interval. The median value for each case was also calculated (Fig. 12a, dotted lines).

On precipitation days, the moisture convergence showed a negative value at $1,000-400 \mathrm{hPa}$ and a positive value at 400-300 hPa (Fig. 13a). The distribution of the median value was almost identical to that of the mean value.
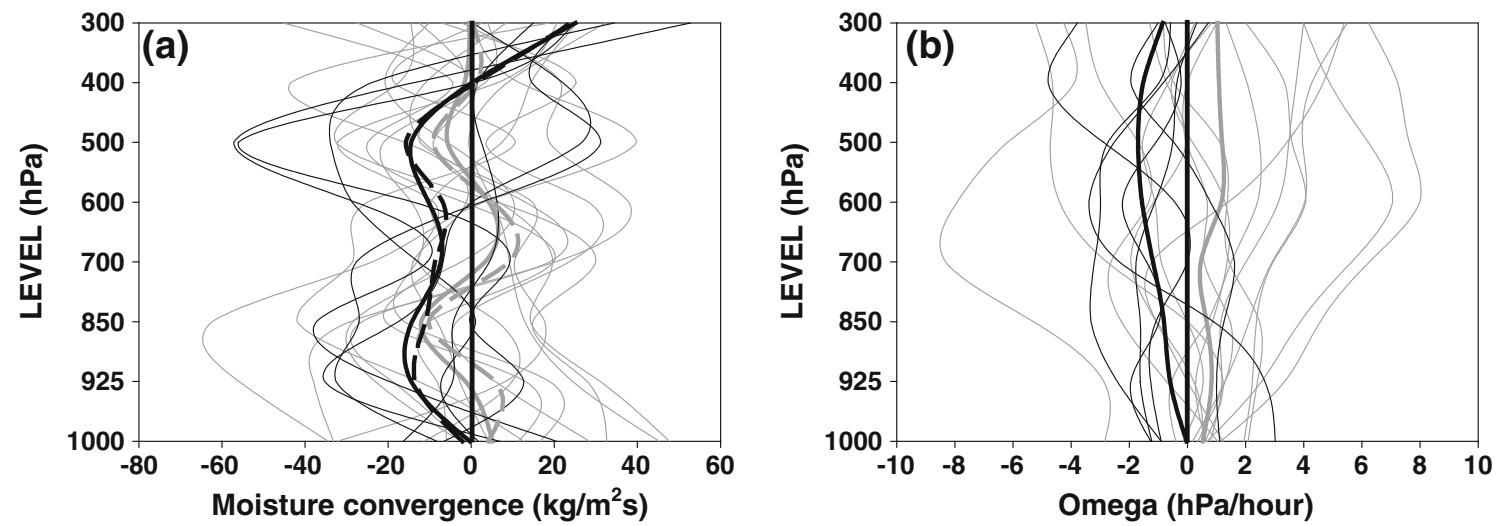

Fig. 13 Mean distribution of the vertical moisture convergence $\left(\mathrm{kg} / \mathrm{m}^{2} \mathrm{~s}\right)$ and omega $(\mathrm{hPa} / \mathrm{h})$ during precipitation and no precipitation for cases with an extreme CAPE in Gwangju station. Solid black and dark gray lines indicate the mean on days without and with precipitation, respectively 
(a)

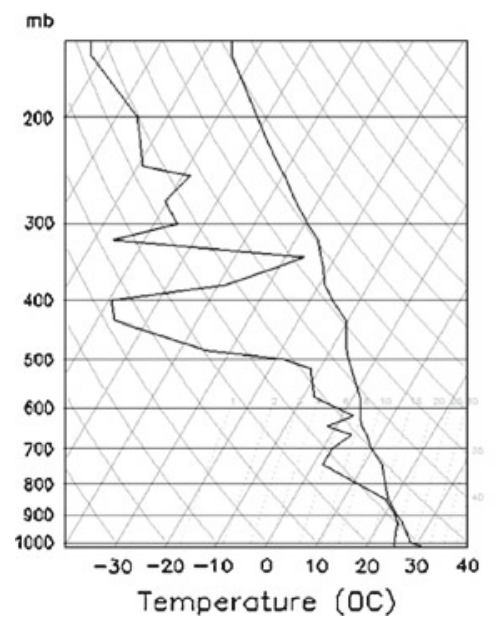

(b)

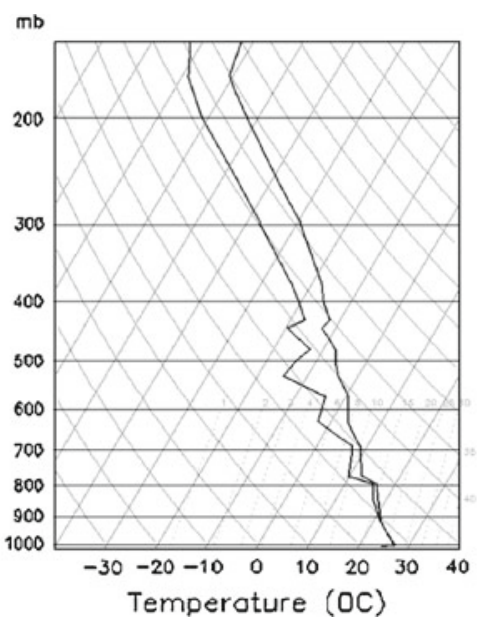

(c)

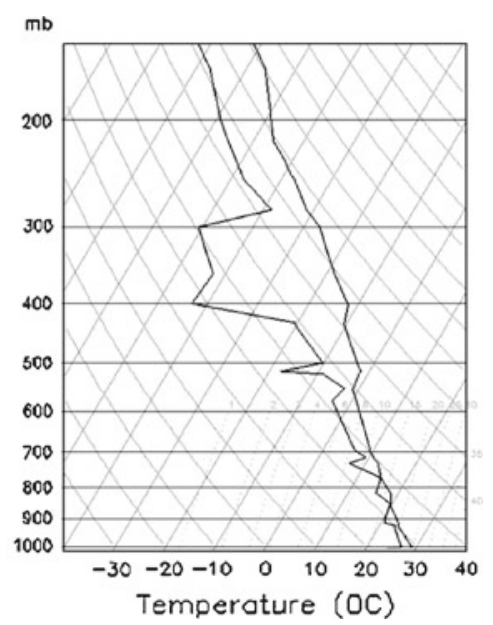

(d)

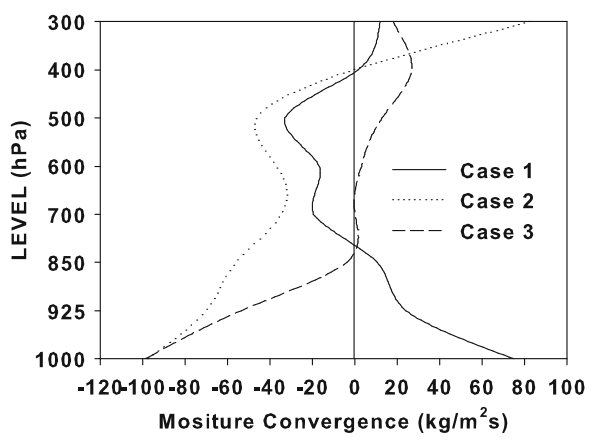

Fig. 14 Skew-T log-P diagrams for a August 3, 2006, b August 28, 2007, and c August 3, 2007. d Vertical distribution of moisture convergence from 1,000 to $300 \mathrm{hPa}$ in three cases. The moisture convergence in these cases is negative

Omega was negative in all levels $(1,000-300 \mathrm{hPa})$ (Fig. 13b). This indicates that showery rain on days with very unstable atmospheric conditions occurred when the vertical flow distribution of air was favorable for the development of thunderstorms through convergence in the lower layer and divergence in the upper layer, and characterized by the continuity of ascending air current from the lower layer.

But, on no precipitation days, the moisture divergence appears in the lower layer and the descending air current has a positive Omega value in all layers (Fig. 13a, b). It is most likely due to the absence of water vapor convergence in the lower layer, and therefore no ascending air current; even when ascending air current was present, such current was not sufficient to overcome the CIN in the lower layer.
For more detailed analysis, we selected three cases with similar CAPE value in GJ (Fig. 14). Case 1 was for $5.0^{\circ} \mathrm{C}$ of surface dew-point depression $\left(31.0^{\circ} \mathrm{C}\right.$ of surface temperature) and a dry state in the middle or upper layers. Case 2 was for $2.3^{\circ} \mathrm{C}$ of surface dew-point depression $\left(27.0^{\circ} \mathrm{C}\right.$ of surface temperature) and a moist state in all layers. Comparing these two cases, we see no precipitation in case 1 while precipitation of $20.5 \mathrm{~mm}$ occurred in case 2 . The state of strong real latent instability was shown in both cases (Table 5), but in case 1 the dew-point depression on the surface was too large to condense the air, and therefore no precipitation occurred. This is due to the fact that formation and development of showery rain and squall lines have a negative correlation with the surface dew-point depression (Myers 1964). No formation of convective cloud

Table 5 Stability indices and environmental parameters of three cases with a very unstable sounding in Gwangju

\begin{tabular}{llllcccccccc}
\hline CASE & Date & CAPE & NCAPE & Surface temperature & Dew-point depression & LI & KI & SWEAT & PW & Rainfall \\
\hline 1 & August 3, 2006 & 3,725 & 4.39 & 31.0 & 5.0 & -6.8 & 35.2 & 252.4 & 58.5 & - \\
2 & August 28, 2007 & 3,743 & 4.20 & 27.0 & 2.3 & -7.8 & 41.4 & 279.0 & 63.6 & 20.5 \\
3 & August 3, 2007 & 3,469 & 3.87 & 28.8 & 4.4 & -5.9 & 39.6 & 287.1 & 65.1 & - & \\
\hline
\end{tabular}


occurred, and therefore no precipitation. Case 3 showed a relatively dry state at $300-400 \mathrm{hPa}$, but very moist state in the middle or low layers as in Case 2. However, precipitation did not occur. This is because the surface dew-point depression $4.4^{\circ} \mathrm{C}\left(28.8^{\circ} \mathrm{C}\right.$ of surface temperature) was relatively high as in case 1 , compared with case 2 . As for the moisture convergence, there was the convergence region from the surface to $400 \mathrm{hPa}$ in Case 2 (Fig. 14d). As the vertical axis of well developed moisture convergence is accompanied by the development of strong cumulus convection (Hudson 1970), it is an indication that enough water vapor for the development of precipitation was present in case 2 . On this day, a thunderstorm actually occurred in the morning and showery rain occurred in the late afternoon. The moisture divergence region appeared in the lower layer in case 1 while the moisture convergence region appearing in the lower layer $(1,000$ and $925 \mathrm{hPa})$, but moisture divergence region was at a level over $850 \mathrm{hPa}$ in Case 3, failing to produce precipitation.

\section{Summary}

We investigated the temporal and spatial distributions of convective energy in the upper layer and the probability and the degree of precipitation in a state of real latent instability, using the frequency distribution and extreme value of the climatological environmental parameters and stability indices derived from rawinsonde data in six stations in Korea for a period for 8 years (2001-2008).

As a result, the mean distribution of CAPE showed that the convective energy in the upper layer in Korea was generally concentrated in late afternoon during the summer. The convective energy was scattered more in inland regions than in coastal regions, as shown by the high positive energy in the upper layer in the observation stations in the following order: GJ, OS, GS, PH, SC, and BYD. This was confirmed in the examination of averages on a day of real latent instability for the environmental parameters (LCL, LFC, EL, and depth of FCL) and the mean dew-point depression at $925 \mathrm{hPa}$ by regions. This result was also confirmed from the frequency distribution of extreme values of stability indices (LI, CAPE, KI, and SWEAT) in summer obtained according to regions.

The analysis of the characteristics of the environmental parameters and CAPE during conditions of precipitation in Korea shows that the LCL and LFC occurred at low altitudes and the EL was at high altitudes, and therefore, the depth of FCL was extensive. In the empirical cumulative probability distribution of CAPE and CIN in the presence and absence of precipitation, the CAPE values do not show discernable differences; the CIN values show a high frequency of small values in the case of precipitation. However, there are cases of no precipitation with extremely high CAPE and almost zero CIN. Although an atmosphere with high CAPE and low CIN is favorable for the occurrence of precipitation, zero CIN does not ensure the occurrence of precipitation. Therefore, it is necessary to cause precipitation using CAPE and the trigger, which is to cause air to ascend from the surface to the CAPE layer. This ascent is attributed to positive buoyancy, which ensures the ascent of air near the earth's surface when it is heated to temperatures greater than the convection temperature through ground heating (naturally or artificially).

In the case of GJ with high CAPE, the analysis of moisture convergence and omega shows that the ascending air current due to convergence of water vapor in the lower layer developed into precipitation. This means that the condensation of air due to small dew-point depression on the surface and the vertical distribution of water vapor convergence play a more important role than the amount of water vapor in the lower layer.

The result of this study can be used to build a model that would take into account local conditions, the optimum region and scale of ground heating and vertical atmospheric conditions, and simulate the conditions for precipitation formation. Additionally, if the ground temperature forcing simulation using local model base on this result is studied, the detailed result (optimum region for ground heating, scale of ground heating and vertical atmospheric conditions, the precipitation formation or not and the estimated precipitation if formed, etc.) on the probability of the creation of artificial showery rain will be drawn there from.

Acknowledgment This work was funded by the Korea Meteorological Administration Research and Development Program under Grant CATER 2006-2306.

Open Access This article is distributed under the terms of the Creative Commons Attribution Noncommercial License which permits any noncommercial use, distribution, and reproduction in any medium, provided the original author(s) and source are credited.

\section{References}

American Meteorological Society (1992) Planned and inadvertent weather modification. A Policy Statement of the American Meteorological Society as adopted by the Council. Available at: http://www.ametsoc.org/policy/wxmod.html

American Meteorological Society (1998) Planned and inadvertent weather modification. A Policy Statement of the American Meteorological Society as adopted by the Council. Available at: http://www.ametsoc.org/policy/wxmod98.html

Belentsova VA (1966) Forecasting of thunderstorms in North Caucasus, Trudy Vysokogornogo Geofizicheskog Institude No 5

Bischoff SA, Canziani PO, Yuchechen AE (2007) The tropopause at southern extratropical latitudes: Argentina operacional rawinsonde climatology. Int J Climatol 27:189-209

Blanchard DO (1998) Assessing the vertical distribution of convective available potential energy. Wea Forecasting 13:870-877 
Brooks HE, Lee JW, Craven JP (2003) The spatial distribution of severe thunderstorm and tornado environments from global reanalysis data. Atmos Res 67-68:73-94

Byun HR, Cho SJ (1981) On the characteristics and forecasting of thunderstorms during Summer in the Central Area of Korea (Abstract in English). J of Korean Met Society 17:28-34

Centre for Ecology \& Hydrology: CEH (2005). Available at: http:// www.ceh.ac.uk

Chuda T, Niino H (2005) Climatology of environmental parameters for mesoscale convections in Japan. J Meteorol Soc Jpn 83:391-408

Cotton (1986) Testing, implementation, and evolution of seeding concepts-A review. Rainfall Enhancement-A Scientific Challenge. Meteor Monogr No. 43 Amer Meteor Soc 139-1491

Craven JP, Brooks HE (2004) Baseline climatology of sounding derived parameters associated with deep moist convection. Nat Wea Digest 28:13-24

Craven JP, Brooks HE, Hart JA (2002) Baseline climatology of sounding derived parameters associated with deep, moist convection. Preprints, 21 st conference on severe local storms. Am Meteor Soc, San Antonio, TX. pp 643-646

Derubertis D (2006) Recent trends in four common stability indices derived from U.S. radiosonde observations. J Climate 19:309-323

Doswell CAIII, Rasmussen EN (1994) The effect of neglecting the virtual temperature correction on CAPE calculations. Wea Forecasting 9:625-629

Eom HS, Suh MS, Ha JC, Lee YH, Lee HS (2008) Climatology of stability indices and environmental parameters derived from rawinsonde data over South Korea. J Asia Pac Atmospheric science 44:269-286

Giordano LA (1994) A fingertip guide to key stability and shear index values used in evaluating severe weather and flash flood potential. National Weather Service Eastern Region, ERH Tech. Attachment 94-4, p 7

Heo BH, Kim HE, Min KD (1994) Synoptic thermodynamic characteristics of air mass thunderstorms occurring in the middle region of South Korea during the summer (Abstract in English). J Korean Met Society 30:49-63

Ho CH, Kang IS (1988) The variability of precipitation in Korea (Abstract in English). J Korean Met Society 24:38-48

Hudson HR (1970) On the relationship between horizontal moisture convergence and convective cloud formation. J Appl Meteorol 10:755-762

Indian Institute of Tropical Meteorology (2009) Cloud aerosol interaction and precipitation enhancement experiment (CAIPEEX). Available at: http://www.tropmet.res.in/static page.php?page id=94
Iwasaki H, Miki T (2001) Observational study on the diurnal variation in precipitable water associated with the thermally induced local circulation over the "semi-basin" around Maebashi using GPS data. J Meteorol Soc Jpn 79:1077-1091

Iwasaki H, Miki T (2002) Diurnal variation of convective activity and precipitable water over the "Semi-Basin". J Meteorol Soc Jpn 80:439-450

Johns RH, Davies JM, Leftwich PW (1993) Some wind and instability parameters associated with strong and violent tornadoes, part II. The tornado: its structure, dynamics, predictions and hazards. Geophy Monogr no. 79, Amer Geophys Union. pp 583-590

Kim KI, Lee HR (1994) Development mechanism of summertime air mass thunderstorm occurred in Kwangju area (Abstract in English). J Korean Met Society 30:597-613

Lucas C, Zipser EJ, LeMone MA (1994) Vertical velocity in oceanic convection off tropical Australia. J Atmos Sci 51:3182-3193

Miller RC (1972) Notes on analysis and severe-storm forecasting procedures of the Military Warning Center. Air Weather Service (MAC).Technical Report 200, Scott Air Force Base. p 181

Myers J (1964) Preliminary radar climatology of central Pennsylvania. J Appl Meteorol 3:421-429

Rasmussen EN, Blanchard DO (1998) A baseline climatology of sounding-derived supercell and tornado forecast parameters. Wea Forecasting 13:1148-1164

Romero R, Gayà M, Doswell CAIII (2007) European climatology of severe convective storm environmental parameters: A test for significant tornado events. Atmos Res 83:389-404

Schultz DM, Schumacher PN, Doswell CAIII (2000) The intricacies of instabilities. Mon Weather Rev 128:4143-4148

Seo AS (2001) Artificial rainfall (in Korean). Atmosphere. J Korean Met Society 11:15-26

Son IN, Chun HY, Lee SM, Lee TY (2000) A numerical study on physical processes related to periodic cell regeneration in multicell storm (Abstract in Korean). J Korean Met Society 36:51-64

Stensrud DJ (1996) Importance of low-level jets to climate: a review. J Climate 9:1698-1711

Wang J, Rossow WB, Zhang YC (2000) Cloud vertical structure and its variations from a 20 -year global rawinsonde dataset. J Climate 13:3041-3056

Wilks DS (1995) Statistical methods in the atmospheric sciences. Academic Press, New York, p 467

Zipser EJ, LeMone MA (1980) Cumulonimbus vertical velocity events in GATE. Part II: synthesis and model core structure. J Atmos Sci 37:2458-2469 